DOI:

http://dx.doi.org/10.15448/1983-4012.2016.1.22746

\title{
CONSIDERAÇÕES SOBRE O CONCEITO DE “ESTADO DE EXCEÇÃO” EM GIORGIO AGAMBEN
}

\author{
Considerations about the concept of "State of Exception" in Giorgio Agamben
}

\author{
José Elielton de Souza*
}

Maria do Socorro Catarina de Sousa Oliveira **

Resumo: O presente trabalho tem por finalidade apresentar o conceito agambeniano de estado de exceção, especialmente na obra homônima Estado de Exceção, explicitando a reconstrução histórica e a análise da teoria e da lógica por trás de sua evolução e consequências.

Palavras-chave: Giorgio Agamben. Direito. Política. Estado de exceção.

\begin{abstract}
This paper aims to present Agamben's concept state of exception, specially the eponymous work State of Exception, explaining the historical reconstruction and analysis of the theory and rationale behind its evolution and consequences.
\end{abstract}

Keywords: Giorgio Agamben. Law. Politics. State of Exception.

\footnotetext{
* Doutor em Filosofia pela Pontifícia Universidade Católica do Rio Grande do Sul (PUCRS); Professor de Filosofia na Universidade Federal do Piauí (UFPI). Contato: jose_elielton@yahoo.com.br

** Graduada em Direito pelo Centro de Educação Unificado de Teresina (CEUT). Contato: catarinaoliveira.juspi@gmail.com
}

\begin{tabular}{|c|c|l|l|l|l|}
\hline intuitio & $\begin{array}{c}\text { ISSN } \\
1983-4012\end{array}$ & Porto Alegre & Vol.9- $\mathrm{N}^{\circ} .1$ & $\begin{array}{l}\text { Julho } \\
2016\end{array}$ & p.131-147 \\
\hline
\end{tabular}




\section{Introdução}

O filósofo italiano Giorgio Agamben é um dos pensadores mais instigantes da atualidade. Conhecido inicialmente pela edição italiana da obra de Walter Benjamin, Agamben vem se tornando uma referência internacional não apenas na filosofia, mas também em estética, religião, política, ontologia e arte, passando a se dedicar principalmente à filosofia política a partir da década de 1990. Seus escritos, consagrados em muitas universidades europeias e norte-americanas, vêm ganhando espaço nos círculos de debates brasileiros, principalmente no que diz respeito à teoria política, ao direito e à literária.

A obra Estado de Exceção ${ }^{l}$ faz parte de um projeto filosófico mais amplo, o "Projeto Homo Sacer", do qual fazem parte ainda Homo Sacer: o poder soberano e a vida nua $I^{2}$ e $O$ que resta de Auschwitz $^{3}$ - um conjunto de livros que, apesar de escritos e publicados fora de ordem, seguem um rigoroso programa de pensamento ${ }^{4}$. Estruturada em seis capítulos, nela Agamben explicita e reconstrói a categoria 'estado de exceção' e desenvolve seu estudo sobre esta figura jurídico-política definindo-a como uma zona de indistinção que está dentro e fora do direito. Além disso, ele expõe sua preocupação com a política de segurança adotada pelos estados modernos, a qual relega os seres humanos a uma falsa segurança jurídica pautada na suspensão da própria ordem jurídica. O desenvolvimento dessa abordagem sobre o estado de exceção se dá sob as influências de Carl Schmitt e de Walter Benjamin ${ }^{5}$, os quais fornecem subsídios para que o filósofo romano discorra sobre soberania, poder e violência.

Nesse sentido, o presente trabalho tem por finalidade apresentar o conceito agambeniano de estado de exceção, explicitando a reconstrução histórica e a análise da teoria e da lógica por trás de sua evolução e consequências.

\footnotetext{
${ }^{1}$ AGAMBEN, Giorgio. Estado de Exceção. Tradução de Iraci D. Poleti. São Paulo: Boitempo, 2004.

2 AGAMBEN, Giorgio. Homo Sacer: o poder soberano e a vida nua I. Tradução de Henrique Burigo. Belo Horizonte: Editora da UFMG, 2007.

${ }^{3}$ AGAMBEN, Giorgio. O que resta de Auschwitz: o arquivo e a testemunha. Tradução de Selvino J. Assmann. São Paulo: Boitempo, 2008.

${ }^{4}$ Daniel A. Nascimento afirma que "concebido em conjunto, o projeto demonstra não somente que uma linha interna de argumentação funciona como elo de ligação entre as partes lançadas separadamente, como um mesmo método é aí cuidadosamente escolhido e empregado. Todo o projeto de investigação é atravessado por um método ao mesmo tempo arqueológico, porque escava e remexe o solo sedimentado, e paradigmático, porque quer encontrar paradigmas que sirvam de referência" (NASCIMENTO, Daniel Arruda. Do fim da experiência ao fim do jurídico: percurso de Giorgio Agamben. 2010. Tese (Doutorado em Filosofia) - Programa de Pós-Graduação em Filosofia da Universidade de Campinas. Campinas, 2010., p. 87-88).

${ }^{5}$ Evandro Pontel observa que "o paradoxal destes dois referenciais é a peculiaridade de ambos. Schmitt, católico e estritamente envolvido com o nacional-socialismo, enquanto Benjamin, judeu alemão, militante antifascista, se suicidou em decorrência de tal sistema. Não obstante a isso, é notável os instigantes e ricos debates estabelecidos entre estes pensadores, sobretudo nas questões que dizem respeito à política. Na esteira destes dois grandes pensadores, Agamben estabelece um diálogo explícito, reconstruindo as posições a respeito do estado de exceção como chave hermenêutica para entender algumas consequências genealógicas desta categoria PONTEL, Evandro. Estado de exceção em Giorgio Agamben. Revista Opinião Filosófica, v. 03, nº 02, p. 97-105, 2012, p. 99-100).
}

\begin{tabular}{|c|c|c|c|c|c|}
\hline intuitio & $\begin{array}{c}\text { ISSN } \\
1983-4012\end{array}$ & Porto Alegre & Vol.9- $\mathrm{N}^{\circ} .1$ & $\begin{array}{l}\text { Julho } \\
2016\end{array}$ & p.131-147 \\
\hline
\end{tabular}




\section{Breve história do conceito de estado de exceção}

O termo "estado de exceção", comum na doutrina alemã, é conhecido nas doutrinas italiana e francesa, como decretos de urgência e estado de sítio (político ou fictício), respectivamente. Na doutrina anglo-saxônica, prevalecem, os termos martial law (lei marcial) e emergency powers (poderes de emergência). Agamben afirma que o termo - que já é utilizado pelos juristas alemães para indicar os poderes excepcionais do presidente do Reich segundo o art. 48 da Constituição de Weimar - foi retomado e desenvolvido por Frederick M. Watkins ("The Problem of Constitutional Dictatorship", in Public Policy 1, 1940) e por Carl J. Friedrich (Consitutional Government and Democracy, 1941) e, enfim, por Clinton L. Rossiter (Constitutional Dictatorship: Crisis Government in the Modern Democracies, 1948) - antes deles Agamben menciona somente o livro do jurista sueco Hebert Tingsten, Les pleins pouvoirs: l'expansion des pouvoirs gouvernamentaux pendant et après la Grande Guerre (1934). Esses livros, embora muito diferentes entre si e, em geral, mais dependentes da teoria schmittiana do que possa parecer, são igualmente importantes porque registram, pela primeira vez, a transformação dos regimes democráticos em paradigma constitutivo da ordem jurídica. ${ }^{6}$

Nesse sentido, a história do termo "estado de sítio fictício ou político" é instrutiva. Ele é característico dos países tradicionalmente adeptos de um Direito escrito. Examinando a genealogia deste termo, Agamben demonstra que a origem do instituto estado de sítio remonta à Revolução Francesa, especificamente no decreto da Assembleia Constituinte de 08 de julho de 1791, o qual distinguia estado de paz (état de paix), em que as autoridades militares e civis deveriam agir cada uma na sua devida esfera de atuação; estado de guerra (état de guerre), quando as autoridades civis deveriam seguir as determinações das autoridades militares; e estado de sítio (état de siège) quando todas as funções originalmente exercidas pela autoridade civil, como a manutenção da ordem e da política interna, passaria para a esfera de responsabilidade da autoridade militar. Inicialmente o citado decreto se feria somente às praças-fortes e aos portos militares, posteriormente se estendeu aos municípios do interior até se chegar ao ponto de poder se declarar qualquer cidade em estado de sítio. ${ }^{7}$

Assim, este estado de sítio adquire as características de um estado de sítio fictício ou político, notadamente com a lei do Diretório de 27 de agosto de 1797, e, posteriormente, com o decreto napoleônico de 24 de dezembro de 1811, que permitia ao imperador declarar o estado de sítio independentemente da situação efetiva de uma cidade sitiada ou diretamente ameaçada pelas forças inimigas. Em face disso, Agamben afirma que "a história posterior do estado de sítio é a história de sua progressiva emancipação em relação à situação de guerra à qual estava ligado na origem, para ser usado,

\footnotetext{
${ }^{6}$ AGAMBEN, Giorgio. Estado de Exceção. Tradução de Iraci D. Poleti. São Paulo: Boitempo, 2004. P. 18.

${ }^{7}$ AGAMBEN, Giorgio. Estado de Exceção. Tradução de Iraci D. Poleti. São Paulo: Boitempo, 2004. P. 15-16
}

\begin{tabular}{|c|c|l|l|l|l|}
\hline intuitio & ISSN & Porto Alegre & Vol.9- $\mathrm{N}^{\mathrm{o}} .1$ & $\begin{array}{l}\text { Julho } \\
2016\end{array}$ & p.131-147 \\
\hline
\end{tabular}


em seguida, como medida extraordinária de polícia em caso de desordens e sedições internas, passando, assim, de efetivo ou militar a fictício ou político". ${ }^{8}$

Segundo Agamben, a ideia de uma suspensão da constituição aparece pela primeira vez na Constituição de 22 frimário [terceiro mês do calendário da primeira república francesa, de 21 de novembro a 20 de dezembro], a qual previa a suspensão das normas constitucionais que protegiam as liberdades individuais como único meio de proteger o estado democrático. A cidade ou região em questão era declarada hors la Constitution (fora da constituição). Embora, de um lado (estado de sítio), o paradigma seja a extensão em âmbito civil dos poderes que são da esfera militarem tempo de guerra e, de outro, uma suspensão da constituição (ou das normas constitucionais que protegem as liberdades individuais), "os dois modelos acabam, com o tempo, convergindo para um único fenômeno jurídico que chamamos estado de exceção" ". Nesse sentido, em ambos os casos, temos um típico estado de exceção, o qual era tido como um mecanismo essencialmente extrajurídico de proteção da ordem jurídica, uma suspensão provisória do regime democrático para salvaguardar a própria democracia ${ }^{10}$.

No âmbito do direito alemão, o termo utilizado para se referir ao estado de exceção é "ditadura constitucional", termo já utilizado pelos juristas alemães para indicar os poderes excepcionais do presidente do Reich segundo o art. 48 da Constituição de Weimar. Agamben recorre aos pensadores acima mencionados (Frederick M. Watkins, Carl J. Friedrich e Clinton L. Rossiter) para examinar como ocorreu a transformação dos regimes democráticos em consequência da progressiva expansão dos poderes do executivo durante as duas guerras mundiais e, de modo, mais geral, do estado de exceção que as havia acompanhado e seguido:

Eles são, de algum modo, os artefatos que anunciam o que hoje temos claramente diante dos olhos, ou seja, que, a partir do momento em que 'o estado de exceção [...] tornou-se a regra', ele não só sempre se apresenta muito mais como uma técnica de governo do que como uma medida excepcional, mas

\footnotetext{
${ }^{8}$ AGAMBEN, Giorgio. Estado de Exceção. Tradução de Iraci D. Poleti. São Paulo: Boitempo, 2004. P. 16. ${ }^{9}$ AGAMBEN, Giorgio. Estado de Exceção. Tradução de Iraci D. Poleti. São Paulo: Boitempo, 2004. P. 17.

${ }^{10}$ Para Daniel A. Nascimento, "o que surpreende é que o instituto do estado de exceção tenha surgido justamente na tradição revolucionária republicana e não na tradição do poder absolutista. [...] A motivação revolucionária, embalada pela aversão ao poder absoluto e pelos ideais metajurídicos da liberdade e igualdade, não foi suficiente para impedir o nascimento conjunto da regra e da exceção. Se, com a ebulição do pensamento revolucionário moderno, ao contrário do que ocorria no século do poder absolutista, o novo governo deve se submeter às leis que promulga e que são promulgadas por outros órgãos imbuídos da função (princípios da sujeição à lei e separação dos poderes), deve algum dispositivo atribuir ao governo a faculdade de suspender a vigência da lei, sempre que necessário. Trata-se de uma preocupação com a governabilidade: nos casos que exigem uma força fora do normal, a normalidade não pode ser um empecilho e precisa cair. Justifica-se então o estado de exceção. Mesmo no interior das democracias e em defesa do sistema democrático. Em algumas ocasiões, a necessidade de um governo forte surge para garantir a permanência da democracia fragilizada e a sua restauração futura. Por isso continua o instituto previsto em uma grande quantidade de países" (NASCIMENTO, Daniel Arruda. Do fim da experiência ao fim do jurídico: percurso de Giorgio Agamben. 2010. Tese (Doutorado em Filosofia) - Programa de Pós-Graduação em Filosofia da Universidade de Campinas. Campinas, 2010. p. 121-122).
}

\begin{tabular}{|c|c|l|l|l|l|}
\hline intuitio & $\begin{array}{c}\text { ISSN } \\
1983-4012\end{array}$ & Porto Alegre & Vol.9- $\mathrm{N}^{\mathrm{o}} .1$ & $\begin{array}{l}\text { Julho } \\
2016\end{array}$ & p.131-147 \\
\hline
\end{tabular}


Considerações sobre o conceito de "Estado de Exceção" em Giorgio Agamben também deixa aparecer sua natureza de paradigma constitutivo da ordem jurídica $^{11}$

Segundo Agamben, um exame da situação do estado de exceção nas tradições jurídicas dos Estados ocidentais mostra uma divisão - clara quanto ao princípio, mas de fato muito mais nebulosa entre ordenamentos que regulamentam o estado de exceção no texto da constituição ou por meio de uma lei, e ordenamentos que preferem não regulamentar explicitamente o problema. Ao primeiro grupo pertencem a França (onde nasceu o estado de exceção moderno, na época da Revolução) e a Alemanha; ao segundo, a Itália, a Suíça, a Inglaterra e os Estados Unidos. Também a doutrina se divide, respectivamente, entre autores que defendem a oportunidade de uma previsão constitucional ou legislativa do estado de exceção e outros, dentre os quais se destaca Carl Schmitt, que criticam sem restrição a pretensão de se regular por lei o que, por definição, não pode ser normatizado.

Contudo, Agamben ressalva que ainda que, no plano da constituição formal, a distinção seja indiscutivelmente importante (visto que pressupõe que, no segundo caso, os atos do governo, realizados fora da lei ou em oposição a ela, podem ser teoricamente considerados ilegais e devem, portanto, ser corrigidos por um bill of indemnity especial): "naquele da constituição material, algo como um estado de exceção existe em todos os ordenamentos mencionados; e a história do instituto, ao menos a partir da Primeira Guerra Mundial, mostra que seu desenvolvimento é independente de sua formalização constitucional ou legislativa"12.

Com relação à Alemanha e à Itália, por exemplo, é importante não esquecer esse contemporâneo processo de transformação das constituições democráticas entre as duas guerras mundiais quando se estuda o nascimento dos chamados regimes ditatoriais na Itália e na Alemanha. "Sob a pressão do paradigma do estado de exceção, é toda a vida politico-constitucional das sociedades ocidentais que, progressivamente, começa a assumir uma nova forma que, talvez, só hoje tenha atingido seu pleno desenvolvimento" "13. Para Agamben, a história do art. 48 da Constituição de Weimar é tão estreitamente entrelaçada com a história da Alemanha de entre as duas guerras, que não é possível compreender a ascensão de Hitler ao poder sem uma análise preliminar dos usos e abusos desse artigo nos anos que vai de 1919 a 1933. Nesse período, em mais de 250 oportunidades, foram promulgados diversos decretos de urgência que decretavam desde a prisão de militantes comunistas, até a pena de morte.

Agamben ressalta, entretanto, que não é tão evidente que Hitler provavelmente não assumiria o poder se o Parlamento estivesse funcionando e o país não estivesse há quase três anos sob o regime da ditadura presidencial fundamentado no discurso schmittiano de que o presidente agia como "guardião da

\footnotetext{
${ }^{11}$ AGAMBEN, Giorgio. Estado de Exceção. Tradução de Iraci D. Poleti. São Paulo: Boitempo, 2004. P. 18.

${ }^{12}$ AGAMBEN, Giorgio. Estado de Exceção. Tradução de Iraci D. Poleti. São Paulo: Boitempo, 2004. P. 22-23.

${ }^{13}$ AGAMBEN, Giorgio. Estado de Exceção. Tradução de Iraci D. Poleti. São Paulo: Boitempo, 2004. P. 16.
}

\begin{tabular}{|c|c|c|c|c|c|}
\hline intuitio & $\begin{array}{c}\text { ISSN } \\
1983-4012\end{array}$ & Porto Alegre & Vol.9 $-\mathrm{N}^{\circ} .1$ & $\begin{array}{l}\text { Julho } \\
2016\end{array}$ & p.131-147 \\
\hline
\end{tabular}


constituição". Segundo ele, "o fim da República de Weimar mostra, ao contrário e de modo claro, que uma "democracia protegida" não é uma democracia e que o paradigma da ditadura constitucional funciona, sobretudo, como uma fase de transição que leva fatalmente à instauração de um regime totalitário"14.

De fato, é na Alemanha nazista que Agamben encontra os traços mais marcantes de um verdadeiro estado de exceção. Assim que Hitler assume o poder, ele proclama, em 28 de fevereiro de 1933, o decreto em favor da proteção do povo e do Estado, suspendendo todos os artigos da Constituição de Weimar que garantiam as liberdades individuais. "O decreto nunca foi revogado, de modo que se pode do ponto de vista jurídico, considerar o conjunto do Terceiro Reich como um estado de exceção que durou 12 anos"15. Por isso, o filósofo define o totalitarismo moderno como "a instauração, por meio do estado de exceção, de uma guerra civil legal que permite a eliminação física não só dos adversários políticos, mas também de categorias inteiras de cidadãos que, por qualquer razão, pareçam não integráveis ao sistema político"16.

Agamben apresenta um interesse particular, sob o ponto de vista da legislação por meio de decretos-lei, pela história e a situação jurídica do estado de exceção na Itália, a qual funcionou como um laboratório político-jurídico do processo que se estenderia pela Europa, com algumas diferenças. O instrumento que deveria ser adotado como medida excepcional de produção normativa passou a ser usado como uma fonte recorrente de lei. Em 1926 uma lei fascista chegou a regulamentar a matéria, permitindo a promulgação por decreto real das normas com força de lei nos casos extraordinários de necessidade e de urgência, necessidade esta que deveria ser apreciada pelo Parlamento. Entretanto, com a perda de autonomia das Câmaras durante o regime fascista, tal apreciação se tornou ineficaz. Posteriormente, em 1939, com a regulamentação dos decretos-lei na Constituição Republicana, a medida tornou-se a regra na Itália.

Isso significa que o parlamento não é mais o órgão soberano a quem compete o poder exclusivo de obrigar os cidadãos pela lei: ele se limita a ratificar os decretos emanados do poder executivo. Em sentido técnico, a República não é mais parlamentar e, sim, governamental. E é significativo que semelhante transformação da ordem constitucional, que hoje ocorre em graus diversos em todas as democracias ocidentais, apesar de bem conhecida pelos juristas e pelos políticos, permaneça totalmente despercebida por parte dos cidadãos. ${ }^{17}$

Partindo para a Inglaterra, o filósofo pondera que o único dispositivo jurídico que poderia ser comparado com o état de siège francês é conhecido pelo nome de martial Law. Porém, o que deveria ser entendido como um direito de guerra, fundamentado no estado de necessidade, se estendeu aos cidadãos

\footnotetext{
${ }^{14}$ AGAMBEN, Giorgio. Estado de Exceção. Tradução de Iraci D. Poleti. São Paulo: Boitempo, 2004. P. 29.

15 AGAMBEN, Giorgio. Estado de Exceção. Tradução de Iraci D. Poleti. São Paulo: Boitempo, 2004. P. 12.

${ }^{16}$ AGAMBEN, Giorgio. Estado de Exceção. Tradução de Iraci D. Poleti. São Paulo: Boitempo, 2004. P. 13.

${ }^{17}$ AGAMBEN, Giorgio. Estado de Exceção. Tradução de Iraci D. Poleti. São Paulo: Boitempo, 2004. P. 32-33.
}

\begin{tabular}{|c|c|l|l|l|l|}
\hline intuitio & $\begin{array}{c}\text { ISSN } \\
1983-4012\end{array}$ & Porto Alegre & Vol.9- $\mathrm{N}^{\mathrm{o}} .1$ & $\begin{array}{l}\text { Julho } \\
2016\end{array}$ & p.131-147 \\
\hline
\end{tabular}


(Emmergency Powers Act) em 29 de outubro de 1920, período de greves e tensões sociais. A medida conferia ao executivo todo o poder necessário para manter a ordem e criava tribunais especiais para os transgressores da lei, o que para Agamben significava que "o princípio do estado de exceção acabava de ser firmemente introduzido no direito inglês" 18 .

Por fim, uma teoria do estado de exceção na constituição norte-americana pode ser percebida na dialética histórica entre os poderes do presidente e os do Congresso. Agamben cita exemplos históricos, como durante a guerra civil (1861-1865), período em que presidente Lincoln agiu como um ditador absoluto, ignorando o Congresso ao editar sozinho medidas provisórias que suspendiam o direito ao habbeas corpus, impunham censura aos correios e a autorizavam a prisão e detenção em cárceres militares de pessoas suspeitas de práticas desleais e traiçoeiras, justificando suas ações de violação à Constituição por um suposto estado de necessidade pública; os poderes extraordinários conferidos a Franklin Roosevelt ao alegar urgência nacional e a própria atitude de Bush, após os ataques de 11 de setembro. Nesse último aspecto, Agamben entende que "a partir do momento em que o poder soberano do presidente se funda essencialmente na emergência ligada a um estado de guerra, a metáfora bélica que tornou-se, no decorrer do século XX, parte integrante do vocabulário político presidencial sempre que se trata de impor decisões consideradas de importância vital"19.

\section{A definição de estado de exceção}

Para Agamben não existe uma teoria do estado de exceção no direito público, tendo em vista que tanto especialistas em direito público, quanto juristas não o consideram como um problema jurídico, mas como um fato político. Assim, sua tarefa teórica está muito clara: "é essa terra de ninguém, entre o direito público e o fato político e entre a ordem jurídica e a vida, que a presente pesquisa se propõe a explorar" ${ }^{20}$.

Contudo, estudar o estado de exceção significa enfrentar três grandes indeterminações, quais sejam, a terminológica, a de locus e a conceitual, esta última, objeto da presente seção. No primeiro aspecto, o filósofo esclarece que embora algumas culturas prefiram utilizar os termos estado de necessidade (Alemanha), decretos de urgência (Itália) ou estado de sítio (França), "se servirá do sintagma 'estado de exceção' como termo técnico para o conjunto coerente dos fenômenos jurídicos que se propõe a definir" e que a própria escolha do termo "estado de exceção" já indica uma "tomada de posição quanto à natureza do fenômeno que se propõe a estudar e quanto à lógica mais adequada à sua compreensão"21.

No que diz respeito à sua localização, encontramos na doutrina jurídica divergências de entendimento quanto à posição do fenômeno em relação ao ordenamento jurídico, existindo aqueles que o

\footnotetext{
${ }^{18}$ AGAMBEN, Giorgio. Estado de Exceção. Tradução de Iraci D. Poleti. São Paulo: Boitempo, 2004. P. 34.

${ }^{19}$ AGAMBEN, Giorgio. Estado de Exceção. Tradução de Iraci D. Poleti. São Paulo: Boitempo, 2004. P. 36.

${ }^{20}$ AGAMBEN, Giorgio. Estado de Exceção. Tradução de Iraci D. Poleti. São Paulo: Boitempo, 2004. P. 12.

${ }^{21}$ AGAMBEN, Giorgio. Estado de Exceção. Tradução de Iraci D. Poleti. São Paulo: Boitempo, 2004. P. 15.
}

\begin{tabular}{|c|c|c|c|c|c|}
\hline intuitio & $\begin{array}{c}\text { ISSN } \\
1983-4012\end{array}$ & Porto Alegre & Vol.9 $-\mathrm{N}^{\circ} .1$ & $\begin{array}{l}\text { Julho } \\
2016\end{array}$ & p.131-147 \\
\hline
\end{tabular}


insere no mundo das normas e outros que o consideram como um fenômeno extrajurídico. Em que pesem as citadas divergências, Agamben afirma que, na verdade, o estado de exceção não é nem exterior nem interior ao ordenamento jurídico e o problema de sua definição diz respeito a um patamar, ou a uma zona de indiferença, em que dentro e fora não se excluem, mas se indeterminam. "A suspensão da norma não significa sua abolição e a zona de anomia por ela instaurada não é (ou, pelo menos, não pretende ser) destituída de relação com a ordem jurídica"22.

Segundo ele, uma opinião recorrente aponta como fundamento do estado de exceção o conceito de necessidade. O termo "necessidade" pode ser entendido em dois sentidos opostos: "a necessidade não reconhece nenhuma lei" e "a necessidade cria sua própria lei". Em ambos os casos, "a teoria do estado de exceção se resolve integralmente na do status necessitatis, de modo que o juízo sobre a subsistência deste esgota o problema da legitimidade daquele. Um estudo da estrutura e do significado do estado de exceção pressupõe, portanto, uma análise do conceito jurídico de necessidade". ${ }^{23}$ Nesse sentido, a teoria da necessidade não é aqui outra coisa que não teoria da exceção em virtude da qual um caso particular escapa à obrigação da observância da lei. A necessidade não é fonte de lei e tampouco suspende, em sentido próprio, a lei; ela se limita a subtrair um caso particular à aplicação literal da norma: "aquele que, em caso de necessidade, age além do texto da lei, não julga a lei, mas o caso particular em que vê que a letra da lei não deve ser observada" ${ }^{24}$.

Para Agamben, o estado de exceção, enquanto figura da necessidade, apresenta-se - ao lado da revolução e da instauração de fato de um ordenamento constitucional - como uma medida "ilegal", mas perfeitamente "jurídica e constitucional", que se concretiza na criação de novas normas ou de uma nova ordem jurídica. Nesse sentido, o status necessitatis apresenta-se, assim, tanto sob forma do estado de exceção quanto sob a forma da revolução, "como uma zona ambígua e incerta onde procedimentos de fato, em si extra ou antijurídicos, transformam-se em direito e onde as normas jurídicas se indeterminam em mero fato; um limiar portanto, onde fato e direito parecem tornar-se indiscerníveis ${ }^{25}$. O conceito de necessidade é, portanto, totalmente subjetivo, relativo ao objetivo que se quer atingir. A tentativa de resolver o estado de exceção no estado de necessidade choca-se, assim, com tantas e mais graves aporias quanto o fenômeno que deveria explicar: "não só a necessidade se reduz, em última instância, a uma decisão, como também aquilo sobre o que ela decide é, na verdade, algo indecidível de fato e de direito". ${ }^{26}$ Agamben elabora seu conceito de estado de exceção a partir de sua leitura de Carl Schmitt ${ }^{27}$ : "a

${ }^{22}$ AGAMBEN, Giorgio. Estado de Exceção. Tradução de Iraci D. Poleti. São Paulo: Boitempo, 2004. 39.

${ }^{23}$ AGAMBEN, Giorgio. Estado de Exceção. Tradução de Iraci D. Poleti. São Paulo: Boitempo, 2004. P. 40.

${ }^{24}$ AGAMBEN, Giorgio. Estado de Exceção. Tradução de Iraci D. Poleti. São Paulo: Boitempo, 2004. P. 41.

${ }^{25}$ AGAMBEN, Giorgio. Estado de Exceção. Tradução de Iraci D. Poleti. São Paulo: Boitempo, 2004. P. 45.

${ }^{26}$ AGAMBEN, Giorgio. Estado de Exceção. Tradução de Iraci D. Poleti. São Paulo: Boitempo, 2004. P. 47.

${ }^{27}$ Para Glauco Barsalini, “embora se utilize de conceitos formulados por Carl Schmitt, Agamben não é seu discípulo. Se exceção e soberania, que conduzem Schmitt à formulação da expressão ditadura soberana inspiram a leitura de

\begin{tabular}{|c|c|l|l|l|l|}
\hline intuitio & ISSN & Porto Alegre & Vol.9- $\mathrm{N}^{\mathrm{o}} .1$ & $\begin{array}{l}\text { Julho } \\
2016\end{array}$ & p.131-147 \\
\hline
\end{tabular}


tentativa mais rigorosa de construir uma teoria do estado de exceção é obra de Carl Schmitt, principalmente em Die Diktatur [1921] e em Politische Theologie [Teologia Política], publicado um ano mais tarde ${ }^{, 28}$. Esses dois livros descrevem, com uma profecia por assim dizer interessada, um paradigma, uma forma de governo, que não só permanece atual, como atingiu hoje seu pleno desenvolvimento ${ }^{29}$.

Apesar da influência de Schmitt, ao contrário dele, em Agamben o político não antecede o jurídico, bem como o jurídico não precede o político ${ }^{30}$ : "se a exceção é a estrutura da soberania, a soberania não é, então, nem um conceito exclusivamente político, nem uma categoria exclusivamente jurídica, nem uma potência externa ao direito (Schmitt), nem a norma suprema do ordenamento jurídico (Kelsen): ela é a estrutura originária na qual o direito se refere à vida e a inclui em si através da própria suspensão"31. Agamben tem consciência de que o objetivo de Carl Schmitt é mostrar que o estado de exceção está inserido num contexto jurídico, embora aquele signifique a suspensão de toda ordem jurídica: o aporte específico da teoria schmittiana é exatamente o de tornar possível a articulação entre estado de exceção e a ordem jurídica. "Trata-se de uma articulação paradoxal, pois o que deve ser inscrito no direito é algo essencialmente exterior a ele, isto é, nada menos que a suspensão da própria ordem jurídica"32.

Para Agamben, a doutrina schmittiana do estado de exceção procede estabelecendo, no corpo do direito, uma série de cesuras e divisões cujos termos são irredutíveis um ao outro, mas que, pela sua articulação e oposição, permitem que a máquina do direito funcione:

Considere-se a oposição entre normas do direito e normas de realização do direito, entre a norma e sua aplicação concreta. A ditadura comissária mostra que o momento da aplicação é autônomo em relação à norma enquanto tal e que a norma 'pode ser suspensa sem, no entanto, deixar de estar em vigor' [...]. Representa, pois, um estado da lei em que esta não se aplica, mas permanece em vigor. Em contrapartida, a ditadura soberana, em que a velha constituição não existe mais e a nova está presente sob a forma 'mínima' do poder constituinte, representa um estado da lei em que esta se aplica, mas não esta formalmente em vigor. $^{33}$

Agamben sobre o Estado Moderno e o poder na sociedade contemporânea, o método schmittiano que se ergue sobre a ideia de que o político precede o jurídico politizando toda e qualquer forma de expressão jurídica, não corresponde à ótica de Agamben" (BARSALINI, Glauco. Estado de exceção permanente: soberania, violência e direito na obra de Giorgio Agamben. 2011. Tese (Doutorado em Filosofia) - Programa de Pós-Graduação em Filosofia da Universidade de Campinas. Campinas, 2011. p. 08).

${ }^{28}$ AGAMBEN, Giorgio. Estado de Exceção. Tradução de Iraci D. Poleti. São Paulo: Boitempo, 2004. P. 53

${ }^{29}$ AGAMBEN, Giorgio. Estado de Exceção. Tradução de Iraci D. Poleti. São Paulo: Boitempo, 2004. P. 53.

${ }^{30}$ Como observa Guilherme A. C. Abdalla, Agamben, muito longe de aceitar o paradoxo schmittiano, pretende oporse a ele, pois coloca de lado a discussão dentro/fora do estado de exceção em relação ao ordenamento jurídico, porquanto essa posição 'parece ser insuficiente para dar conta do fenômeno que deveria explicar', e indica a relação resultante como de uma exclusão inclusiva (ABDALLA, Guilherme de Andrade Campos. O Estado de Exceção em Giorgio Agamben: Contribuições ao Estudo da Relação Direito e Poder. 2010. Dissertação (Mestrado em Direito) Programa de Pós-Graduação em Direito da Universidade de São Paulo. São Paulo, 2010, p. 104).

${ }^{31}$ AGAMBEN, Giorgio. Estado de Exceção. Tradução de Iraci D. Poleti. São Paulo: Boitempo, 2004. P. 35.

${ }^{32}$ AGAMBEN, Giorgio. Estado de Exceção. Tradução de Iraci D. Poleti. São Paulo: Boitempo, 2004. P. 54.

${ }^{33}$ AGAMBEN, Giorgio. Estado de Exceção. Tradução de Iraci D. Poleti. São Paulo: Boitempo, 2004. P. 58.

\begin{tabular}{|c|c|l|l|l|l|}
\hline intuitio & $\begin{array}{c}\text { ISSN } \\
1983-4012\end{array}$ & Porto Alegre & Vol.9- $\mathrm{N}^{\circ} .1$ & $\begin{array}{l}\text { Julho } \\
2016\end{array}$ & p.131-147 \\
\hline
\end{tabular}


O estado de exceção separa, pois, a norma de sua aplicação para tomar possível a aplicação, introduzindo no direito uma zona de anomia para tomar possível a normatização efetiva do real. Para exemplificar melhor como isso ocorre, Agamben recorre ao sintagma de "força de lei". Este sintagma vincula-se a uma longa tradição no direito romano e no medieval, onde tem o sentido geral de eficácia, de capacidade de obrigar, sendo somente na época moderna, no contexto da Revolução Francesa, que ele começa a indicar o valor supremo dos atos estatais expressos pelas assembleias representativas do povo ${ }^{34}$. Entretanto, observa o filósofo, é determinante que, em sentido técnico, o sintagma "força de lei" se refira, tanto na doutrina moderna quanto na antiga, não à lei, mas àqueles decretos que o poder executivo pode, em alguns casos - particularmente, no estado de exceção - promulgar: “o conceito 'força-de-lei', enquanto termo técnico do direito, define, pois, uma separação entre a vis obligandi ou a aplicabilidade da norma e sua essência formal, pela qual decretos, disposições e medidas, que não são formalmente leis, adquirem, entretanto, sua 'força", 35 .

A força de lei pretende desfazer a separação entre a aplicação e a norma (cuja aplicação foi suspensa), produzindo uma exceção paradoxal que aplica a lei ao prevê justamente a sua desaplicação, numa tentativa violenta de manter vigente uma norma que não condiz mais com a realidade. $\mathrm{O}$ estado de exceção é, nesse sentido, "a abertura de um espaço em que aplicação e norma mostram sua separação e em que uma pura força de lei realiza (isto é, aplica desaplicando) uma norma cuja aplicação foi suspensa"36. Desse modo, a união impossível entre norma e realidade, e a consequente constituição do âmbito da norma, é operada sob a forma de exceção, isto é, pelo pressuposto de sua relação. Isso significa que, para aplicar uma norma, é necessário, em última análise, suspender sua aplicação, produzir uma exceção. Para Agamben, "em todos os casos, o estado de exceção marca um patamar onde lógica e práxis se indeterminam e onde uma pura violência sem logos pretende realizar um enunciado sem nenhuma referência real" ${ }^{37}$.

Para explicar essas aporias que a teoria moderna do estado de exceção não consegue resolver, Agamben recorre ao iustitium do direito romano, visto que este permite observar o estado de exceção em sua forma paradigmática. O termo iustitium significa literalmente "interrupção", "suspensão" do direito, pois neste período havia uma suspensão não apenas da administração da justiça, mas uma cessação do próprio direito. Agamben observa que "é o sentido desse paradoxal instituto jurídico, que consiste unicamente na produção de um vazio jurídico, que se deve examinar aqui, tanto do ponto de vista da sistemática do direito publico quanto do ponto de vista filosófico-político"38.

\footnotetext{
${ }^{34}$ AGAMBEN, Giorgio. Estado de Exceção. Tradução de Iraci D. Poleti. São Paulo: Boitempo, 2004. P. 60.

${ }^{35}$ AGAMBEN, Giorgio. Estado de Exceção. Tradução de Iraci D. Poleti. São Paulo: Boitempo, 2004. P. 60.

${ }^{36}$ AGAMBEN, Giorgio. Estado de Exceção. Tradução de Iraci D. Poleti. São Paulo: Boitempo, 2004. P. 63.

${ }^{37}$ AGAMBEN, Giorgio. Estado de Exceção. Tradução de Iraci D. Poleti. São Paulo: Boitempo, 2004. P. 63.

${ }^{38}$ AGAMBEN, Giorgio. Estado de Exceção. Tradução de Iraci D. Poleti. São Paulo: Boitempo, 2004. P. 68.
}

\begin{tabular}{|c|c|c|c|c|c|}
\hline intuitio & $\begin{array}{c}\text { ISSN } \\
1983-4012\end{array}$ & Porto Alegre & Vol.9 $-\mathrm{N}^{\circ} .1$ & $\begin{array}{l}\text { Julho } \\
2016\end{array}$ & p.131-147 \\
\hline
\end{tabular}


Agamben recorre ao conceito de tumultus, particularmente em sua relação com o conceito de guerra, para analisar o estado de exceção no iustitum romano:

Uma analise das passagens de Lívio [Tito Lívio] relativas ao tumultus mostra, na verdade, que a causa do tumulto pode ser (mas nem sempre é) uma guerra externa, mas que o termo designa tecnicamente o estado de desordem e de agitação (tumultus tem afinidade com tumor, que significa inchaço, fermentação) que resulta, em Roma, desse acontecimento (assim, a notícia de uma denota na guerra contra os etruscos provoca em Roma um tumulto e maiorem quam re terrorem. ${ }^{39}$

Nesse sentido, tumulto não é a guerra repentina, mas a magna trepidatio que ela produz em Roma. Por isso, o termo pode designar, em outros casos, a desordem que se segue a uma insurreição interna ou a uma guerra civil.

A única definição possível que permite compreender todos os casos atestados é a que vê no tumultus 'a cesura através da qual, do ponto de vista do direito público, se realiza a possibilidade de medidas excepcionais' [...]. A relação entre bellum e tumultus é a mesma que existe, de um lado, entre guerra e estado de sido militar e, de outro, entre estado de exceção e estado de sítio politico. ${ }^{40}$

Assim, seja resultante de uma insurreição interna, seja de uma guerra civil, o tumultus era o pressuposto necessário para se realizar as medidas excepcionais, ou seja, produzia-se um vácuo jurídico como único meio capaz de reestabelecer a ordem e, consequentemente manter o controle do Estado. Nesse sentido, o iustitium responde, portanto, à necessidade de "romper" o ordenamento jurídico para salvá-lo.

Apesar disso, o iustitium, enquanto efetua uma interrupção e uma suspensão de toda ordem jurídica, não pode ser interpretado segundo o paradigma da ditadura, pois não há a criação de uma nova magistratura: se na constituição romana, o ditador era uma figura especifica de magistrado escolhido pelos cônsules, cujo imperium, extremamente amplo, era conferido por uma lex curiata que definia seus objetivos; no iustitium, ao contrário (mesmo quando declarado por um ditador no cargo), não existe criação de nenhuma nova magistratura; o poder ilimitado de que gozam de fato iusticio indicto os magistrados existentes resulta não da atribuição de um imperium ditatorial, mas da suspensão das leis que tolhiam sua ação ${ }^{41}$.

$\mathrm{Na}$ medida em que são produzidos num vazio jurídico, os atos cometidos durante o iustitium são radicalmente subtraídos a toda determinação jurídica. Caso se quisesse, a qualquer preço, dar um nome a uma ação realizada em condições de anomia, seria possível dizer que aquele que age durante o institium não executa nem transgredi, mas inexecuta o direito. Nesse sentido, "suas ações são meros fatos cuja apreciação, uma vez caduco o institium, dependerá das circunstâncias; mas, durante o institium, não são

${ }^{39}$ AGAMBEN, Giorgio. Estado de Exceção. Tradução de Iraci D. Poleti. São Paulo: Boitempo, 2004. P. 68.

${ }^{40}$ AGAMBEN, Giorgio. Estado de Exceção. Tradução de Iraci D. Poleti. São Paulo: Boitempo, 2004. P. 69.

${ }^{41}$ AGAMBEN, Giorgio. Estado de Exceção. Tradução de Iraci D. Poleti. São Paulo: Boitempo, 2004. P. 74-75

\begin{tabular}{|c|c|l|l|l|l|}
\hline intuitio & $\begin{array}{c}\text { ISSN } \\
1983-4012\end{array}$ & Porto Alegre & Vol.9- $\mathrm{N}^{\circ} .1$ & $\begin{array}{l}\text { Julho } \\
2016\end{array}$ & p.131-147 \\
\hline
\end{tabular}


absolutamente passíveis de decisão e a definição de sua natureza - executiva ou transgressiva e, no limite, humana, bestial ou divina - está fora do âmbito do direito" ${ }^{\text {" }}$.

É a essa indefinibilidade e a esse não-lugar que responde a ideia de uma força-de-lei. A suspensão da lei libera uma força que não qualifica, mas justifica diversos atos; é a típica força-de-lei tentando ser apropriada pelo poder constituinte e constituído, simultaneamente ${ }^{43}$. Assim, a força-de-lei, separada da lei, o imperium flutuante, a vigência sem aplicação e a ideia de uma espécie de 'grau zero' da lei, são algumas das tantas ficções por meio das quais o direito tenta incluir em si sua própria ausência e apropriar-se do estado de exceção, ou, no mínimo, assegurar uma relação com ele ${ }^{44}$.

\section{Luto político, Auctoritas e Potestas}

Feita essa longa exposição genealógica sobre a origem e os desdobramentos do conceito de estado de exceção, resta a Agamben investigar ainda duas questões: primeiramente, explicar como o termo iustitium - designação técnica para o estado de exceção - adquiriu o significado de luto público pela morte do soberano e, posteriormente, analisar qual o fundamento do poder atribuído ao Senado para emitir o senatus consultum ultimum por meio do qual pedia aos cônsules que tomasse qualquer medida considerada necessária para a salvação do Estado.

Quanto à primeira questão, com o fim da Republica, o iustitium como suspensão do direito para se enfrentar um tumulto desaparece e o novo significado substitui tão bem o velho que a própria lembrança desse austero instituto parece apagar-se:

Como os períodos de anomia e de crise, em que se assiste a um desmoronamento das estruturas sociais normais e a uma falência dos papeis e das funções que pode chegar à completa inversão dos costumes e dos comportamentos culturalmente condicionados, assim também os períodos de luto são, frequentemente, caracterizados por uma suspensão e uma alteração de todas as relações sociais. Quem define os períodos de crise [...] como uma substituição temporária da ordem pela desordem, da cultura pela natureza, do cosmos pelo chaos, da eunomia pela anomia, define implicitamente os períodos de luto e suas manifestações ${ }^{45}$.

Para Agamben, isso não só explica a evolução do iustitium do sentido de estado de exceção para o luto político pela semelhança entre as manifestações do luto e as da anomia, mas busca a razão última dessa semelhança na ideia de "terror anômico" que caracteriza as sociedades humanas em seu conjunto. Contudo, ele atribui a Augusto Fraschetti,

${ }^{42}$ AGAMBEN, Giorgio. Estado de Exceção. Tradução de Iraci D. Poleti. São Paulo: Boitempo, 2004. P. 78. ${ }^{43}$ AGAMBEN, Giorgio. Estado de Exceção. Tradução de Iraci D. Poleti. São Paulo: Boitempo, 2004. P. 78-80.

${ }^{44}$ AGAMBEN, Giorgio. Estado de Exceção. Tradução de Iraci D. Poleti. São Paulo: Boitempo, 2004. P. 80.

${ }^{45}$ AGAMBEN, Giorgio. Estado de Exceção. Tradução de Iraci D. Poleti. São Paulo: Boitempo, 2004. P. 102.

\begin{tabular}{|c|c|c|c|c|c|}
\hline intuitio & $\begin{array}{c}\text { ISSN } \\
1983-4012\end{array}$ & Porto Alegre & Vol. $9-\mathrm{N}^{\mathrm{o}} .1$ & $\begin{array}{l}\text { Julho } \\
2016\end{array}$ & p.131-147 \\
\hline
\end{tabular}


O mérito de haver evidenciado o significado político do luto público, mostrando que a ligação entre os dois aspectos do iustitium não está num pretenso caráter de luto da situação extrema ou da anomia, mas no tumulto que os funerais do soberano podem provocar. Fraschetti desvenda sua origem nas violentas desordens que haviam acompanhado os funerais de Cesar, definidos significativamente como 'funerais sediciosos'. [...] Fraschetti pode mostrar como, de modo coerente com essa estratégia, a partir da morte de seu sobrinho Marcelo, cada abertura do mausoléu da família devia implicar para Augusto a proclamarão de um iustitium. ${ }^{46}$

Nesse sentido, a correspondência entre anomia e luto torna-se compreensível apenas à luz da correspondência entre morte do soberano e estado de exceção. O elo original entre tumultus e iustitium ainda está presente, mas o tumulto coincide agora com a morte do soberano, enquanto a suspensão do direito torna-se parte integrante da cerimônia fúnebre. Assim, "a novidade constitucional do principado pode ser vista, então, como uma incorporação direta do estado de exceção e da anomia diretamente na pessoa do soberano, que começa a libertar-se de toda subordinação ao direito para se afirmar como legibus solutu" ${ }^{\prime 4}$.

Para Agamben, essa natureza intimamente anômica da nova figura do poder supremo aparece de modo claro na teoria do soberano como "lei viva" (nomos empsychos), que é elaborada no meio neopitagórico durante os mesmos anos em que se afirma o principado:

Se o soberano é um nomos vivo, se, por isso, anomia e nomos coincidem inteiramente em sua pessoa, então a anarquia (que, à sua morte - quando, portanto, a nexo que a une alei e cortado - ameaça libertar-se pela cidade) deve ser ritualizada e controlada, transformando o estado de exceção em luto publico e o luto, em iustitium. À indiscernibilidade de nomos e anomia no corpo vivo do soberano corresponde a indiscernibilidade entre estado de exceção e luto público na cidade. Antes de assumir a forma moderna de uma decisão sobre a emergência, a relação entre soberania e estado de exceção apresenta-se sob a forma de uma identidade entre soberano e anomia. O soberano, enquanto uma lei viva, e intimamente anomos. Também aqui o estado de exceção e a vida - secreta e mais verdadeira - da $1 \mathrm{i}^{48}$.

Nesse sentido, o universo do direito se apresenta, em última instância, como um campo de força percorrido por duas tensões conjugadas e opostas: "uma que vai da norma à anomia e a outra que, da anomia, leva à lei e à regra"49. Disso resulta um duplo paradigma que marca o campo do direito com uma ambiguidade essencial: de um lado, uma tendência normativa em sentido estrito, que visa a cristalizar-se num sistema rígido de normas cuja conexão com a vida é, porém, problemática, senão impossível (o estado perfeito de direito, em que tudo é regulado por normas); de outro lado, uma tendência anômica que

${ }^{46}$ AGAMBEN, Giorgio. Estado de Exceção. Tradução de Iraci D. Poleti. São Paulo: Boitempo, 2004. P. 105. ${ }^{47}$ AGAMBEN, Giorgio. Estado de Exceção. Tradução de Iraci D. Poleti. São Paulo: Boitempo, 2004. P. 106. ${ }^{48}$ AGAMBEN, Giorgio. Estado de Exceção. Tradução de Iraci D. Poleti. São Paulo: Boitempo, 2004. P. 107. ${ }^{49}$ AGAMBEN, Giorgio. Estado de Exceção. Tradução de Iraci D. Poleti. São Paulo: Boitempo, 2004. P. 111.

\begin{tabular}{|c|c|l|l|l|l|}
\hline intuitio & $\begin{array}{c}\text { ISSN } \\
1983-4012\end{array}$ & Porto Alegre & Vol.9- $\mathrm{N}^{\mathrm{o}} .1$ & $\begin{array}{l}\text { Julho } \\
2016\end{array}$ & p.131-147 \\
\hline
\end{tabular}


desemboca no estado de exceção ou na ideia do soberano como lei viva, em que uma força-de-lei privada de norma age como pura inclusão da vida ${ }^{50}$.

Quanto à questão do fundamento do poder atribuído ao Senado, Agamben afirma que este se encontra na auctoritas (autoridade) daquele que podia emitir o senatus consultum ultimum. Ele ressalta, entretanto, que com a categoria auctoritas - especialmente em sua contraposição a potestas ${ }^{51}$ encontramo-nos diante de um fenômeno cuja definição, tanto na história do direito quanto, de modo mais geral, na filosofia e na teoria política, parece esbarrar em obstáculos e aporias quase insuperáveis ${ }^{52}$. Essas dificuldades se deve ao fato de que o conceito de auctoritas refere-se a uma fenomenologia jurídica relativamente ampla, que diz respeito tanto ao direito privado quando ao direito público.

No âmbito privado, Agamben afirma que "auctoritas é a propriedade do auctor, isto é, da pessoa sui iuris (pater famílias) que intervém - pronunciando a fórmula técnica autor fio - para conferir validade jurídica ao ato de um sujeito que, sozinho não pode realizar um ato jurídico válido" ${ }^{\text {53 }}$. Sob a perspectiva do direito público, auctoritas significa uma prerrogativa, por excelência, do Senado romano, consistindo na manifestação (consultum) sobre determinada coisa. No estado romano, o Senado "não pode manifestarse sem ser interrogado pelos magistrados e só pode perguntar ou 'aconselhar' - consultum é o termo técnico - e esse 'conselho' nunca é vinculante de modo absoluto" ${ }^{\text {54 }}$. O Senado romano não decide e nem reivindica. Assim, Agamben distingue auctoritas de potestas: "auctoritas e potestas são claramente distintas e, entretanto, formam juntas um sistema binário" 55 .

Essa relação, ao mesmo tempo de exclusão e de suplementação, entre auctoritas e potestas encontra-se também em outro instituto, em que a auctoritas patrum mostra mais uma vez sua função: o interregnum.

Mesmo depois do fim da monarquia, quando, por morte ou por qualquer outra razão, nao havia mais na cidade nenhum consul ou nenhum outro magistrado (exceto os representantes da plebe), os patres auctores (isto é, o grupo dos

\footnotetext{
${ }^{50}$ AGAMBEN, Giorgio. Estado de Exceção. Tradução de Iraci D. Poleti. São Paulo: Boitempo, 2004. P. 111.

${ }^{51}$ Para Daniel A. Nascimento, ao contrapor esses dois conceitos, Agamben "prepara o terreno para mostrar como auctoritas e potestas, dois elementos tratados historicamente como excludentes entre si e complementares para conferir existência aos atos jurídicos ou políticos, estão, no universo da política contemporânea, unidos e marcam o excesso da atividade estatal na medida em que concentrados numa única fonte de irradiação ou, se preferirmos seguir por uma outra via de observação, auctoritas e potestas estão divorciados: no caso extremo do uso da auctoritas, o estado de exceção, a potestas do povo é suspensa com o direito, para ser reativado onde ela já não possuía vigor" (NASCIMENTO, Daniel Arruda. Do fim da experiência ao fim do jurídico: percurso de Giorgio Agamben. 2010. Tese (Doutorado em Filosofia) - Programa de Pós-Graduação em Filosofia da Universidade de Campinas. Campinas, 2010, p. 126-127).

${ }^{52}$ AGAMBEN, Giorgio. Estado de Exceção. Tradução de Iraci D. Poleti. São Paulo: Boitempo, 2004. P. 115.

${ }^{53}$ AGAMBEN, Giorgio. Estado de Exceção. Tradução de Iraci D. Poleti. São Paulo: Boitempo, 2004. P. 117.

${ }^{54}$ AGAMBEN, Giorgio. Estado de Exceção. Tradução de Iraci D. Poleti. São Paulo: Boitempo, 2004. P. 119.

${ }^{55}$ AGAMBEN, Giorgio. Estado de Exceção. Tradução de Iraci D. Poleti. São Paulo: Boitempo, 2004. P. 120.
}

\begin{tabular}{|c|c|c|c|c|c|}
\hline intuitio & $\begin{array}{c}\text { ISSN } \\
1983-4012\end{array}$ & Porto Alegre & Vol.9- $\mathrm{N}^{\mathrm{o}} .1$ & $\begin{array}{l}\text { Julho } \\
2016\end{array}$ & p.131-147 \\
\hline
\end{tabular}


Um terceiro instituto em que a auctoritas mostra sua função específica de suspensão do direito e a hostis iudicatio. Em situações excepcionais, em que um cidadão romano ameaçasse, através de conspiração ou de traição, a segurança da república, ele podia ser declarado pelo Senado hostis, inimigo publico. "O hostis iudicatus era, antes, radicalmente privado de todo estatuto jurídico e podia, portanto, em qualquer momento, ser destituído da posse de seus bens e condenado à morte. O que é suspenso pela auctoritas não é, aqui, simplesmente a ordem jurídica, mas o ius civis, o próprio estatuto do cidadão romano",57.

A relação, ao mesmo tempo antagônica e complementar entre auctoritas e potestas aparece, enfim, numa particularidade terminológica. Segundo Agamben, o sintagma senatus auctoritas é usado em sentido técnico para designar o senatus-consulto que, à medida que lhe foi oposta uma intercessio, é privado dos efeitos jurídicos e não pode, pois, de modo algum, ser executado:

A auctoritas do Senado aparece, pois, em sua forma mais pura e mais evidente quando é invalidada pela potestas de um magistrado, quando vive como mera escrita em absoluta oposição à vigência do direito. Por um instante, a auctoritas revela aqui sua essência: o poder, que pode "conferir a legitimidade" e, ao mesmo tempo, suspender o direito, mostra seu caráter mais específico no momento de sua ineficácia jurídica máxima" 58

A norma pode, portanto, ser aplicada ao caso normal e pode ser suspensa sem anular inteiramente a ordem jurídica porque, sob a forma da auctoritas ou da decisão soberana, ela se refere imediatamente à vida e dela deriva ${ }^{59}$.

\section{Considerações Finais}

Com essa genealogia do conceito de estado de exceção, Agamben pretende mostrar a ficção que governa o arcanum imperii por excelência de nosso tempo. O sistema jurídico do Ocidente apresenta-se

\footnotetext{
${ }^{56}$ AGAMBEN, Giorgio. Estado de Exceção. Tradução de Iraci D. Poleti. São Paulo: Boitempo, 2004. P. 122.

${ }^{57}$ AGAMBEN, Giorgio. Estado de Exceção. Tradução de Iraci D. Poleti. São Paulo: Boitempo, 2004. P. 123.

${ }_{58}^{58}$ AGAMBEN, Giorgio. Estado de Exceção. Tradução de Iraci D. Poleti. São Paulo: Boitempo, 2004. P. 123.

${ }^{59}$ Como afirma Daniel A. Nascimento, essa conclusão aponta para a crise do conceito de autoridade. E o atestado dessa dissolução ocorre na seguinte situação: quando a autoridade esvaziada é atribuída à figura carismática de um chefe, independentemente do poder no qual possa estar investido. Este é o caso das recentes experiências do século vinte: Hitler e Mussolini. Há, na configuração de um líder carismático, a projeção da imagem paterna (representação dos interesses de toda a nação) e a estetização do chefe (forjado pela figura do gênio romântico), onde autoridade depende unicamente do carisma pessoal, não de qualquer direito preexistente, do qual poderia auferir sua legitimidade. A reivindicação do carisma como atributo daquele revestido de autoridade coincide, porém, com a neutralização da lei e não com uma figura mais original de poder. Em última instância, o fenômeno realiza a pretensão do direito de coincidir com a vida (NASCIMENTO, Daniel Arruda. Do fim da experiência ao fim do jurídico: percurso de Giorgio Agamben. 2010. Tese (Doutorado em Filosofia) - Programa de Pós-Graduação em Filosofia da Universidade de Campinas. Campinas, 2010., p.127).
}

\begin{tabular}{|c|c|l|l|l|l|}
\hline intuitio & $\begin{array}{c}\text { ISSN } \\
1983-4012\end{array}$ & Porto Alegre & Vol.9- $\mathrm{N}^{\mathrm{o}} .1$ & $\begin{array}{l}\text { Julho } \\
2016\end{array}$ & p.131-147 \\
\hline
\end{tabular}


como uma estrutura dupla, formada por dois elementos heterogêneos e, no entanto, coordenados: um elemento normativo e jurídico em sentido estrito - que podemos inscrever aqui, por comodidade, sob a rubrica de potestas - e um elemento anômico e metajurídico - que podemos designar pelo nome de auctoritas. $\mathrm{O}$ elemento normativo necessita do elemento anômico para poder ser aplicado, mas, por outro lado, a auctoritas só pode se afirmar numa relação de validação ou de suspensão da potestas. O estado de exceção é, então, "o dispositivo que deve, em última instância, articular e manter juntos os dois aspectos da máquina jurídico-política, instituindo um limiar de indecidibilidade entre anomia e nomos, entre vida e direito, entre auctoritas e potestas" ${ }^{\prime 60}$. Daí porque para Agamben auctoritas e potestas não podem irradiar de uma mesma figura, sob pena de originar uma máquina letal, a exemplo do nazismo, das medidas do governo americano após o 11 de setembro, de medidas recentes de governos europeus para "conter a islamização de seus países", dentre outras.

Agamben não é muito otimista quanto à possibilidade de retorno ao estado de direito me vigor antes da adoção da exceção como regra, pois o que está em questão agora são os próprios conceitos de 'estado' e de 'direito'. No entanto, "se é possível tentar deter a máquina, mostrar sua ficção central, é porque, entre violência e direito, entre a vida e a norma, não existe nenhuma articulação substancial",61 . Isso significa que no centro do poder sempre constará o estado de exceção, embora nem sempre visível, pois este é um espaço vazio, onde uma ação humana sem relação com o direito se coloca em frente a uma norma sem relação com a vida. O que não quer dizer que a máquina, com seu centro vazio, não seja eficaz; ao contrário, o que ele procura mostrar é justamente, que ela continuou a funcionar quase sem interrupção a partir da Primeira Guerra Mundial, por meio do fascismo e do nacional-socialismo, até nossos dias: "O estado de exceção, hoje, atingiu exatamente seu máximo desdobramento planetário" ${ }^{62}$. O aspecto normativo do direito pode ser, assim, impunemente eliminado e contestado por uma violência governamental que, ao ignorar no âmbito externo o direito internacional e produzir no âmbito interno um estado de exceção permanente, pretende, no entanto, ainda aplicar o direito.

Nesse sentido, o estado de exceção em Agamben se configura como estrutura política fundamental presente em diversas sociedades que se intitulam democráticas, mas que adotam o instituto para os casos de conflitos mais extremos. no centro do poder sempre constará o estado de exceção, por mais invisível que seja a percepção deste, pois este é um espaço vazio, onde uma ação humana sem relação com o direito se coloca em frente a uma norma sem relação com a vida. Essa relação, portanto, mostra que "o direito em sua não relação com a vida e a vida em sua não relação com o direito significa abrir entre eles um espaço para a ação humana que, há algum tempo, reivindicava para si o nome "política",63.

\footnotetext{
${ }^{60}$ AGAMBEN, Giorgio. Estado de Exceção. Tradução de Iraci D. Poleti. São Paulo: Boitempo, 2004. P. 130.

${ }^{61}$ AGAMBEN, Giorgio. Estado de Exceção. Tradução de Iraci D. Poleti. São Paulo: Boitempo, 2004. P. 131-132.

${ }^{62}$ AGAMBEN, Giorgio. Estado de Exceção. Tradução de Iraci D. Poleti. São Paulo: Boitempo, 2004. P. 131.

${ }^{63}$ AGAMBEN, Giorgio. Estado de Exceção. Tradução de Iraci D. Poleti. São Paulo: Boitempo, 2004. P. 13.
}

\begin{tabular}{|c|c|c|c|c|c|}
\hline intuitio & $\begin{array}{c}\text { ISSN } \\
1983-4012\end{array}$ & Porto Alegre & Vol.9- $\mathrm{N}^{\circ} .1$ & $\begin{array}{l}\text { Julho } \\
2016\end{array}$ & p.131-147 \\
\hline
\end{tabular}




\section{Referências}

ABDALLA, Guilherme de Andrade Campos. O Estado de Exceção em Giorgio Agamben: Contribuições ao Estudo da Relação Direito e Poder. 2010. Dissertação (Mestrado em Direito) - Programa de Pós-Graduação em Direito da Universidade de São Paulo. São Paulo, 2010.

AGAMBEN, Giorgio. Estado de Exceção. Tradução de Iraci D. Poleti. São Paulo: Boitempo, 2004.

AGAMBEN, Giorgio. Homo Sacer: o poder soberano e a vida nua I. Tradução de Henrique Burigo. Belo Horizonte: Editora da UFMG, 2007.

AGAMBEN, Giorgio. O que resta de Auschwitz: o arquivo e a testemunha. Tradução de Selvino J. Assmann. São Paulo: Boitempo, 2008.

BARALDI, Tereza Cristina Albieri. Estado de Exceção. Revista Org \& Demo, v. 12, n. 01, p. 115-120, 2011.

BARSALINI, Glauco. Estado de exceção permanente: soberania, violência e direito na obra de Giorgio Agamben. 2011. Tese (Doutorado em Filosofia) - Programa de Pós-Graduação em Filosofia da Universidade de Campinas. Campinas, 2011.

NASCIMENTO, Daniel Arruda. Do fim da experiência ao fim do jurídico: percurso de Giorgio Agamben. 2010. Tese (Doutorado em Filosofia) - Programa de Pós-Graduação em Filosofia da Universidade de Campinas. Campinas, 2010.

PONTEL, Evandro. Estado de exceção em Giorgio Agamben. Revista Opinião Filosófica, v. 03, nº 02, p. 97-105, 2012.

Recebido em: 28/12/2015

Aprovado para a publicação em: 22/04/2016

\begin{tabular}{|c|c|c|c|c|c|}
\hline intuitio & $\begin{array}{c}\text { ISSN } \\
1983-4012\end{array}$ & Porto Alegre & Vol.9- No .1 & $\begin{array}{c}\text { Julho } \\
2016\end{array}$ & p.131-147 \\
\hline
\end{tabular}

